\title{
Tracer Alumni pada STMIK AUB Surakarta Berbasis Android
}

\author{
Isadora Nugroho* ${ }^{* 1}$, Wisnu Wendanto ${ }^{2}$, Zulfa Dadang ${ }^{3}$ \\ ${ }^{13}$ Program Studi Sistem Informasi; ${ }^{2}$ Program Studi Sistem Komputer; \\ ${ }^{123}$ STMIK AUB Surakarta, Indonesia \\ e-mail: *1isadoranu@stmik-aub.ac.id, ${ }^{2}$ wisnu.wendanto@stmik-aub.ac.id, ${ }^{3}$ zulfada@gmail.com
}

\begin{abstract}
Abstrak
Dalam perguruan tinggi tentunya sangat membutuhkan informasi data alumninya seperti jurusan, tahun kelulusan, alamat, pekerjaan, serta informasi lainnya yang berkaitan dengan alumni tersebut. STMIK AUB Surakarta merupakan perguruan tinggi yang melakukan penelusuran terhadap alumni nya, akan tetapi STMIK AUB Surakarta belum mempunyai sistem informasi yang mampu membantu proses penelusuran informasi dan pengolahan data alumni. Tujuan penelitian ini adalah membangun Sistem Informasi Tracer Alumni STMIK AUB Surakarta Berbasis Android yang mampu mengelola dan menyajikan data secara akurat dari para alumni yang ada. Dalam membangun sistem tersebut metode pendekatan yang digunakan adalah metode perancangan dengan menggunakan metode waterfall. Metode pengumpulan data dengan metode wawancara, metode observasi dan metode pustaka.Sebagai alat bantu analisis dan perancangan yang digunakan adalah flowchart, UML (Unified Moddeling Languanges), dan Entity Relationship Diagram. Sedangkan bahasa pemograman pendukung yang digunakan adalah Android Studio versi 3.0.1, PHP, Java,dan My SQL sebagai database. Hasil dari penelitian ini adalah membuat suatu Sistem Informasi Tracer Alumni yang dapat membantu alumni dalam memberikan suatu informasi kepada sesama alumni mapun kepada kampus STMIK AUB Surakarta dan membantu kemahasiswaan dalam mengolah, memberikan, dan menampilkan data alumni.
\end{abstract}

Kata kunci: Aplikasi, Tracer Alumni, Android, PHP

\section{PENDAHULUAN}

Studi penelusuran alumni merupakan proses penelusuran para alumni guna mengetahui gambaran tentang profil, kinerja, serta sebaran lokasi kerja para alumni. Selain itu bagi suatu perguruan tinggi, studi penelusuran alumni yang selanjutnya akan disebut Tracer Study dapat digunakan untuk mengetahui keberhasilan proses pendidikan terhadap anak didiknya, dan juga sebagai indikator keberhasilan pendidikan yang diselenggarakan perguruan tinggi itu sendiri. Dengan kegiatan pelacakan alumni diharapkan kampus mendapatkan informasi indikasi kekurangan pelaksanaan program studi dan menyediakan dasar-dasar pelaksanaan perencanaan dimasa depan. Untuk itu informasi keberhasilan profesionalisme (karier, status, pendapatan) dari para alumni sangat diperlukan.

Alumni merupakan produk dari suatu institusi pendidikan. Kualitas alumni menunjukkan kualitas dari institusi pendidikan tersebut. Fakta tersebut semakin terasa, khususnya untuk alumni perguruan tinggi. Hal ini dikarenakan alumni perguruan tinggi secara langsung akan bersentuhan dengan dunia kerja. STMIK AUB Surakarta tentunya telah memiliki alumni yang sangat banyak. Banyaknya alumni tentunya akan mewarnai kehidupan dalam masyarakat, baik di dalam wilayah Surakarta maupun di luar Surakarta.

STMIK Adi Unggul Birawa Surakarta merupakan suatu perguruan tinggi yang melakukan studi penelusuran alumni. Studi penelusuran alumni di STMIK AUB Surakarta menggunakan media Informasi berupa grup dalam jejaring sosial Facebook dan belum adanya 
prosedur pengolahan data yang tetap. Disamping itu penelusuran alumni selama ini hanya dilakukan ketika waktu - waktu tertentu saja. Selain itu, pengolahan data dilakukan menggukan pencatatan buku dan memasukkan data tersebut kedalam komputer.

Banyaknya lulusan yang tersebar di Surakarta ataupun diluar Surakarta akan sulit jika melakukan pendataan melalui survey maupun dengan kuisioner. Jangkauan sumber informasi yang didapatkan dari alumni dirasa kurang merata, sehingga banyak alumni yang tidak terdata dan mendapatkan informasi seputar kampus. Pendataan-pun akan membutuhkan waktu lama untuk memasukkan data alumni kedalam sebuah buku kelulusan. Proses pendataan di STMIK AUB Surakarta adalah bagian Kemahasiswaan menulis data alumni kedalam buku catatan kelulusan lalu memasukan data ulang ke dalam komputer, kemudian data tersebut di arsipkan. Dilihat dari proses penginputan data alumni tersebut, sehingga menimbulkan data yang bertumpuk. Serta masalah pencarian data alumni yang sulit dilakukan karena harus mencari didata yang bertumpuk sehingga menumbuhkan waktu yang lama. Serta proses yang harus berulang - ulang menuliskan data kedalam buku catatatan lalu memasukkan data kedalam komputer.

Kemudahan Kemahasiswaan dalam pengolahan data alumni menjadi suatu hal yang perlu diperhatikan, maka diperlukan suatu sistem informasi yang dapat mengumpulkan dan mengelola serta menyajikan data secara akurat dari para alumni yang ada. Guna mendapat informasi yang akurat dan mudah dalam pengaksesan datanya, maka informasi dapat dirangkum dalam sebuah sistem informasi Tracer alumni berbasis android dan perlu juga dibangun sebuah sistem informasi yang tentunya dapat mempermudah proses akses data tersebut pada database.

Berdasarkan permasalahan yang ada, maka mendorong penulis untuk membuat "Sistem Informasi Tracer Alumni STMIK AUB Berbasis Android", guna melacak keberadaan alumni, mengetahui alumni yang bekerja maupun belum bekerja sehingga mempermudah pencarian lowongan pekerjaan bagi alumni, mempermudah Kemahasiswaan dalam mengolah, memberikan dan menampilkan data, serta bagi alumni untuk lebih update perkembangan STMIK AUB, maupun ke sesama alumni.

\section{METODE PENELITIAN}

\subsection{Metode Pengambilan Data}

1. Metode Wawancara

Wawancara digunakan sebagai teknik pengumpulan data apabila peneliti ingin melakukan studi pendahuluan untuk menemukan permasalahan yang harus diteliti, tetapi juga apabila peneliti ingin mengetahui hal-hal dari responden yang lebih mendalam. Sugiyono (2013).

2. Metode Observasi

Dalam observasi peneliti terlibat dengan kegiatan sehari-hari orang yang sedang diamati atau yang digunakan sebagai sumber data penelitian.Sugiyono (2013).

3. Metode Pustaka

Metode ini dilakukan dengan cara membaca atau mempelajari buku-buku referensi literature yang berhubungan dengan masalah yang akan dibahas guna memperoleh landasan teori untuk keperluan menganalisa data. Usman dan Akbar (2000).

\subsection{Analisis PIECES}

Untuk mengidentifikasi masalah, maka harus dilakukan analisis terhadap ekonomi, pengendalian, efisiensi dan pelayanan atau juga sering disebut dengan analisis pieces. Adapaun pengertian dari analisis pieces sebagai berikut Al Fatta (2007) :

a. Analisis Kinerja Sistem (Performance)

Sistem yang lama masih menggunakan media kertas dan penginputan data menggunakan Microsoft Excel, dimana BAAK dan Kemahasiswaan harus mengulang penginputan data alumni yang ada pada Microsoft Excel. 
b. Analisis Informasi (Information)

Informasi yang disampaikan tidak update.Karena alumni harus mengunjungi kampus jika ada event yang berkaitan dengan alumni, dan kurangnya informasi tentang alumni untuk kepentingan kampus.

c. Analisis Ekonomi (Economy)

Biaya yang dikeluarkan relatif lebih tinggi, karena masih menggunakan hard file dan harus menyediakan banyak kertas.

d. Analisis Pengendalian (Control)

Keamanan kurang karena seluruh informasi masih menggunakan kertas dan penyimpana di kontak alumnihardisk. Sehingga dapat menyebabkan tidak amannya data. Misalnya : Kertas isisan data Alumni terselip atau hilang, dan data pada hardisk terformat dan tidak bisa di kembalikan lagi. Hal itu sangat menyulitkan BAAK jika harus menginputkan data alumni kembali.

e. Analisis Efisiensi (Efficiency)

Belum efisien, karena keseluruhan kegiatan dilakukan secara manual. Dimana Alumni menuliskan data alumni kemudian BAAK menambahakan data kedalam komputer.

f. Analisis Pelayanan (Service)

Layanannya masih satu arah, alumni harus datang kampus untuk mengisi isian data alumni, dan untuk mengetahui informasi tentang alumni lain.

\section{HASIL DAN PEMBAHASAN}

\subsection{Instalasi Aplikasi Tracer Alumni STMIK AUB Surakarta}

1) Tampilan Aplikasi Tracer Alumni STMIK AUB Surakarta handphone, lalu instal aplikasi tracer alumni.

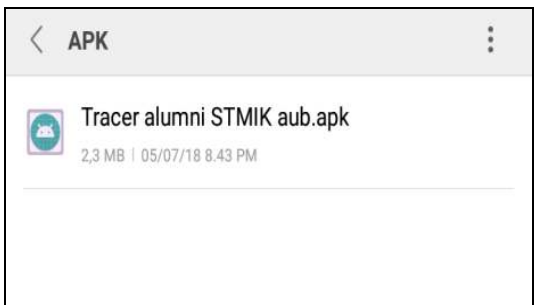

Gambar 1 Instalasi Aplikasi Tracer Alumni

2) Selanjutnya akan muncul tampilan install aplikasi, lalu klik "Pasang".

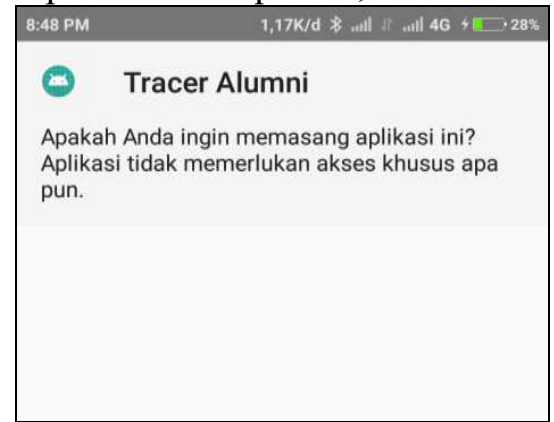

Gambar 2 Pemasangan Aplikasi tracer Alumni

Setelah proses install selesai maka muncul tampilan Login Aplikasi Tracer Alumni STMIK AUB Alumni dapat login dengan memasukkan username dan password. 


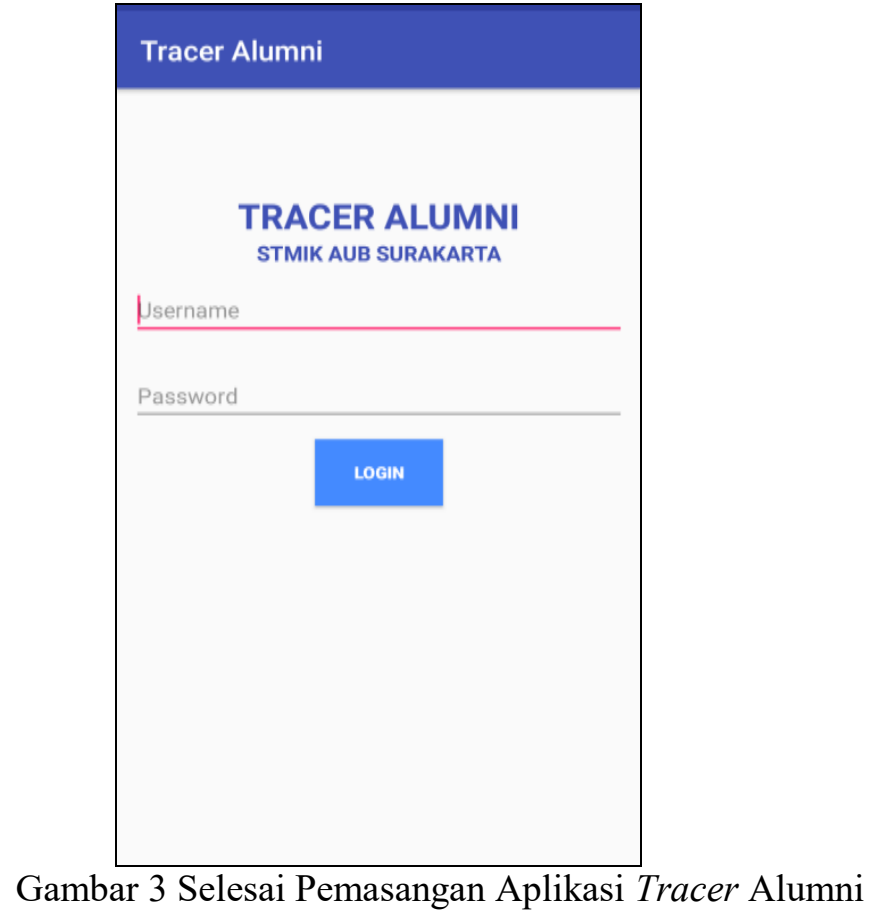

\section{KESIMPULAN}

Hasil perancangan Aplikasi Tracer Alumni pada STMIK AUB Surakarta, jenis dan sumber data menggunakan data premier dan data sekunder. Metode pengumpulan data mengunakan metode wawancara, metode observasi dan metode pustaka. Alur sistem menggunakan Flowchart, UML (Unified Modeling Language) yang tediri dari Usecase Diagram, Activity Diagram, Sequence Diagram, Class Diagram, dan Entity Relationship Diagram. Sedangkan untuk metode pengembangan sistem menggunakan Metode Waterfall. Pengembangan sistem menggunakan Bahasa pemrograman pendukung Android Studio Versi 3.0.1, PHP, Java dan MySQL sebagai pengolahan database. Sistem ini bisa melakukan pengolahan data alumni, data galeri, data berita, dan data lowongan pekerjaan.Adanya Aplikasi Tracer Alumni STMIK AUB Surakarta memberikan media baru bagi alumni dalam menyediakan media bertukar informasi tentang kampus dan juga lowongan pekerjaan. Selain itu juga dilengkapi dengan data alumni, yang bisa dijadikan sebagai tolak ukur kualitas selama lulus dari perguruan tinggi. Sehingga STMIK AUB Surakarta bisa mengukur sejauhmana keberhasilan dalam mendidik hingga siap bekerja. Hasil dari penelitian ini adalah membuat suatu aplikasi Tracer alumni berbasis Android pada STMIK AUB Surkartayang dapat membantu STIMIK AUB dalam memantau lulusannya.

\section{SARAN}

Aplikasi Tracer Alumni pada STMIK AUB Surakarta ini masih dapat dikembangkan lebih lanjut, yaitu: aplikasi yang di buat sekarang ini dapat dikembangkan lagi dengan penambahan sistem Digitalisasi legalisir Ijazah beserta adminitrasi pembayarannya agar alumni dapat dengan mudah melegalisir ijazah tanpa harus datang ke kampus. Aplikasi saat ini dapat dikembangkan lagi dengan Menambahkan sistem forum yang berguna untuk berdiskusi dan saling bertukar pengalaman dengan alumni yang lain. Aplikasi saat ini dapat dikembangkan lagi dengan penambahan validasi otomastis pada login apliksi android agar bagian kemahasiswaan tidak perlu penginputan data secara terus menerus. 


\section{DAFTAR PUSTAKA}

[1] A.S Rosa dan Salahuddin M, 2011. Modul Pembelajaran Rekayasa Perangkat Lunak (Terstruktur dan Berorientasi Objek), Modula, Bandung.

[2] Booch , Grady. 1999. Visual Modeling With Rational Rose 2000 and UML

[3] Coupey, Eloise. 2001. Marketing and the internet. PenticeHall, Inc. New Jersy.

[4] Haryanto, Bambang . 2011. Esensi-esensi Bahasa Pemrograman Java. Yogyakarta: Andi.

[5] Jeffrey. L. Whitten, Lonnie D.Bentley, Kevin C. 2001. System Analysis and Design Methods 5thEd. McGraw-Hill.

[6] Jogiyanto. 2005. Analisis \& Deasin Sistem Informasi.:Pendekatan Terstruktur Teori dan Praktek Aplikasi Bisnis. Yogyakarta : Andi.

[7] Kadir, Abdul. 2014. Pengenalan Sistem Informasi Edisi Revisi. Yogyakarta : Andi.

[8] Kristanto. 2003. Konsep dan Perancangan Basis Data. Yogyakarta : Andi.

[9] Komputer, W. 2006. Pengolahan Database dengan MySQL. Yogyakarta: Andi Offshet.

[10] Munadi, Faisal. 2013. Sistem Informasi Pendataan Alumni BerbasisWeb Pada Stmik U’budiyah Indonesia, Skripsi Sekolah Tinggi Manajemen Informatika Dan KomputerStmik U'budiyah IndonesiaBanda Aceh.

[11] Nugroho, Adi. 2006. E-commerce. Bandung : Informatika Bandung.

[12] Nuri, Alan, (2014), Sistem Informasi Tracer Study Pada Universitas Islam Negeri Raden Fatah Palembang Berbasis Web. Skripsi Jurusan Sistem InformasiFakultas Dakwah Dan KomunikasiUniversitas Islam Negeri Raden FatahPalembang.

[13] Nugroho, Ernes Cahyo, Nugroho, Isadora. Sistem Pusat Karir dan Tracer Study Perguruan Tinggi. Indonesian Journal on Networking and Security, Vol.7 No. 1, ISSN: 2302-5700 (print), ISSN: 2354-6654 (online). 2018.

[14] Roger, S. Pressman, Ph.D. 2012, Rekayasa Perangkat Lunak (Pendekatan Praktisi) Edisi 7 : Buku 1, Yogyakarta: Andi.

[15] Pressman, Roger S. 2001.Rekayasa Perangkat Lunak Pendekatan Praktisi. Yogyakarta : Andi.

[16] Shalahuddin, M dan Rosa. 2015. Rekayasa Perangkat Lunak Tersruktur dan Berorientasi Objek. Bandung : Informatika.

[17] Saleh, Muhammad (2012). Tracer StudyAlumni Fakultas Teknik Universitas Tanjungpura Dengan Sistem Informasi Berbasis Web, Jurnal ELKHA.

[18] Safaat H, Nazruddin. (2012). Pemrograman Aplikasi Mobile Smartphone dan

[19] Tablet PC berbasis Android. Informatika. Bandung.

[20] Subhan, M, (2012), Analisan Perancangan Sistem. Jakarta : Lentera Ilmu Cendekia.

[21] Watung,Ivan A, (2014), Perancangan Sistem Informasi Data Alumni Fakultas Teknik Unsrat Berbasis Web. E-jurbal Teknik Electro dan Komputer, UNSRAT, Manado.

[22] Yakub. (2012). Pengantar Sistem Informasi. Yogyakarta: Graha Ilmu

[23] https://widuri.raharja.info/index.php/SI101446553 